Published in : Ergonomics. Vol. 47, no. 11, 15 sept 2004, pp. 1180-1194

which should be cited to refer to this work

\title{
Consumers' use of written product information
}

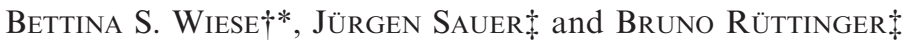 \\ $\dagger$ Department of Psychology, University of Koblenz-Landau, Fortstrasse 7, \\ D-76829 Landau, Germany \\ Institute of Psychology, Darmstadt University of Technology, Hochschulstrasse \\ 1, D-64289 Darmstadt, Germany
}

Keywords: Product information, Instruction manual, Consumer products, Ecological behaviour.

\begin{abstract}
Two studies were conducted to investigate the predictive role of person-specific, product-specific, and situation-specific influences on the use of instruction manuals in the field of electrical consumer products. In a laboratory study, 42 participants were observed while putting a vacuum cleaner into operation. Situational primes (i.e., receiving a verbal cue that the packaging contains an instruction manual) increased the probability of the user manual being read. Additional verbal information that the manual contains information on energysaving behaviours was especially motivating for persons with high environmental concern. Self-report data, collected on a wide range of products, suggest that product complexity is the best predictor of instruction manual use. In a second study with 30 participants, different positions of product labels were compared, i.e. placing the information on the packaging or directly onto the product. Information placed directly onto the product had a significantly higher influence on participants' actual behaviour than providing the same information on the packaging.
\end{abstract}

\section{Introduction}

Whoever buys a technical product will receive an instruction manual. In psychological research, user manuals are mainly investigated from the perspective of instructional psychology (cf. Konoske and Ellis 1991, Ballstaedt 1997) by focusing on the question of how product information should be presented to be understandable and recalled (e.g. Haney 1969, Bieger and Glock 1986, Young and Wogalter 1990, Wogalter and Vigilante 2003). This topic is also dealt with in various popular books on how to write user manuals (e.g. Weiss 1985).

How much, however, do consumers actually make use of instruction manuals? Gebert (1988) conducted a series of studies that provided important insight into the use of instruction manuals. In a survey among visitors to a technology fair, $37 \%$ of the participants reported that they would first try to use a new product without referring to external help. Another study evinced that about a third of the users read only parts of the manual. This is not surprising since many customers think that instruction manuals are too technical, too complicated, and too difficult to read (see Gebert 1988). It is interesting to note that a number of readers reported that they 
expected to find information on how to use a product to save energy and on how to increase its longevity. In addition, Gebert's study revealed that gender influences the frequency of reading instruction manuals: More men than women reported that they would first try to operate a product without referring to the instruction manual. Furthermore, women read instruction manuals more thoroughly than men. Gebert (1988) saw these findings as reflecting traditional role behaviour, with males viewing themselves more competent in the technical domain, therefore not feeling in need of further information on technical products. Furthermore, her results showed that the probability of reading the manual increased with the education levels of the users. This might be explained by the fact that better educated users have fewer difficulties in understanding instructional information. Finally, Gebert reported that perceived necessity of reading the instruction manual is influenced by product complexity, product novelty and price.

Another important questionnaire study on consumers' use of instructions was conducted by Wright et al. (1982) with reference to 60 products (30 electrical products, 30 non-electrical products). On the question, 'How much of the instruction manual would you read?', about $34 \%$ of the participants answered they would read none, $13 \%$ answered that they would read some of the information given, and $53 \%$ answered that they would read the complete manual. Interestingly, the percentage of occasions on which participants said that they would read the instructions was significantly higher for electrical than for non-electrical products. But even within the group of electrical products, the self-reported willingness to (partly or completely) read the manual was not equally distributed since reading probability was significantly higher for complex $(83 \%)$ than for simple products $(70 \%)$. It should be noted, however, that Wright et al. (1982) asked participants to imagine the product to be from a new manufacturer or having a new brand name and to indicate how they would respond to the respective instruction manual. They did not ask participants how they usually reacted to instruction manuals. Therefore, it seems plausible to assume that the actual reading probabilities are lower than those reported by Wright et al. (1992).

Do personality variables also play a role as predictors of referring to instruction manuals? One group of cognitive personality variables that might be considered here, are control and self-efficacy beliefs. Pronounced technology-related control and self-efficacy beliefs are supposed to reflect a successful learning history in the technical domain that results in the user being convinced they are able to solve technical problems easily (see Ertmer et al. 1994, Bandura 1996, Baumert et al. 1998, Beier 1999). So far, technology-specific self-efficacy and control beliefs have mainly been investigated with reference to information technologies (e.g. Henry and Stone 1995, 1997, Torkzadeh et al. 1999). It might be argued, however, that control beliefs concerning handling technical products might also influence the usage of instruction manuals in the field of other technical products such as household appliances. With regard to the use of instruction manuals for domestic appliances, individuals with pronounced technology-related control beliefs may think that they just do not need the information, so they do not refer to the manual. On the other hand, individuals with pronounced technology-related control beliefs might use instruction manuals more often as they have no doubt that they will understand technical descriptions, whereas individuals with low technology-related control beliefs might be concerned that they will not understand them. 
Besides sociodemographic and personality influences, situational cues might enhance the probability of the instruction manual being read. So far, the effect of cueing on the reading probability of instruction manuals has not been investigated. In a consumer decision study with college students, Heslin and Johnson (1992), however, found that an incentive (i.e. a bonus credit point) for choosing the best product (in this case, a typewriter) increased the time participants spent studying product descriptions as well as the amount of information remembered. How well a situational cue is recognized by a user, again, might be influenced by personality variables (e.g. interest). For instance, individuals with high environmental concern might be especially motivated to read a manual when they know that it comprises information on energy-saving behaviour.

Figure 1 illustrates the four classes of factors the authors consider as potentially important for the probability of referring to instruction manuals in the context of technical appliances in the domestic domain, i.e., personality variables, sociodemographic variables, product features, and situational cues. In Study I, examples of each of the four dimensions will be investigated.

\section{Study I: Reading probability for instruction manuals}

The main research question here was aimed at testing the influence of a verbal cue on the actual use of the instruction manual (situational influences; Hypothesis 1: cueing increases reading probability) and at analyzing the potential moderating role of personal interest (Hypothesis 2: high environmental concern increases reading probability if an ecological cue is present). With regard to product-specific influences, product complexity was selected as one important characteristic hypothesizing that high complexity leads to an increasing probability of the instruction manual being read (Hypothesis 3). This assumption was tested referring to self-report data on a wide range of technical products. In addition, based on

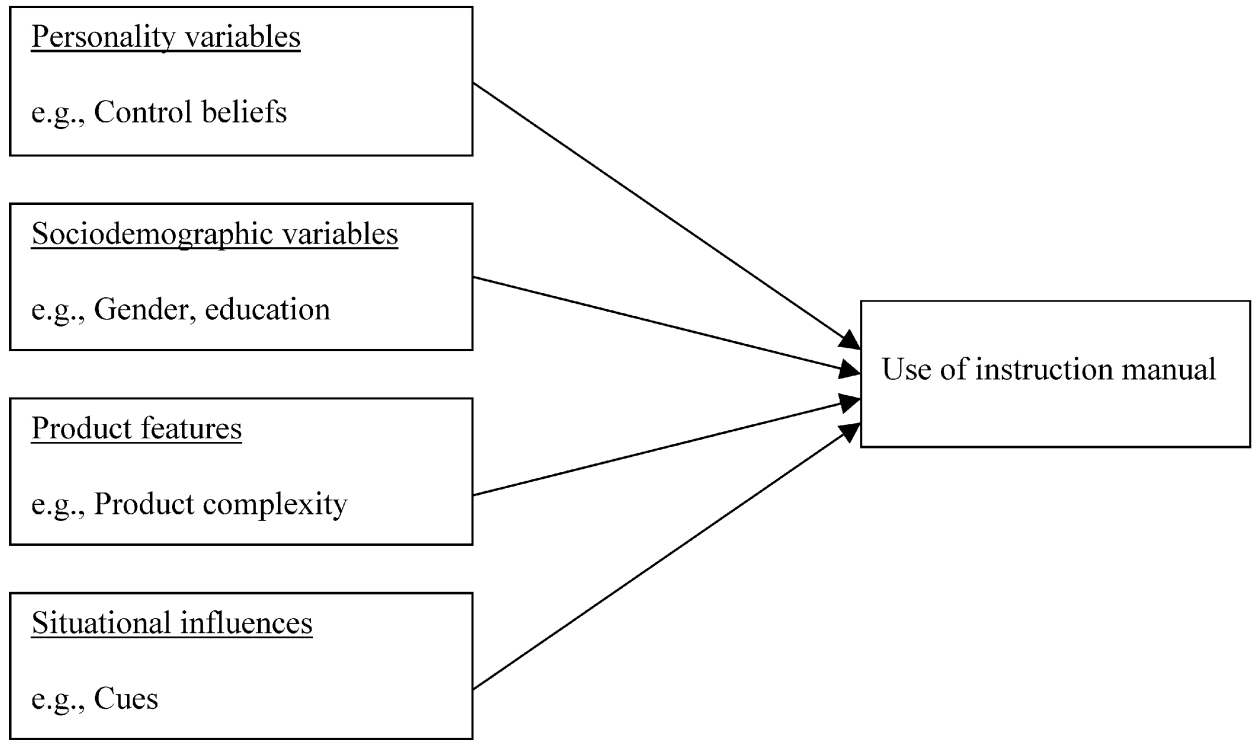

Figure 1. A working model of factors influencing the use of instruction manuals. 
observed as well as self-reported use of instruction manuals, the study explored the predictive power of technical control beliefs (Hypothesis 4) and tested whether the stronger use of instruction manuals by women reported by Gebert (1988) could be replicated (Hypothesis 5). To complement the present approach, Study II compared alternative ways of presenting information in their power of increasing the probability of product information being processed by the user.

\subsection{Methods}

2.1.1. Participants and design: Forty-two participants (25 female; 17 male), aged between 19 and 44 years $(M=25.93$ years, $S D=7.04)$, took part in Study I. Most of them were college students $(83.3 \%)$. They were not paid for participation.

To test the assumption that situational primes would enhance reading probability, a one-factorial design was employed, with primes being varied at three levels: no prime, safety prime, and ecology prime (see below).

2.1.2. Procedure and instruments: The study took place in a laboratory, with participants coming in for individual sessions. Each session lasted about $45 \mathrm{~min}$ and was divided into two parts: a behaviour observation and a questionnaire part.

2.1.2.1. Observation: Participants were given a packed vacuum cleaner which they were asked to unpack and put into operation by cleaning two small carpets. They were randomly assigned to one of three experimental conditions (14 participants in each condition). One group received no cue concerning the instruction manual (no prime group). The second group was told that the package with the vacuum cleaner also contained the instruction manual describing, among other things, how to use it safely (safety prime group). The third group was told that the packaging with the vacuum cleaner also contained the instruction manual, giving, among other things, information on how to use it in an energy-saving way (ecology prime group). During each session, the experimenter recorded whether the participants made use of the instruction manual.

2.1.2.2. Self-report data: Participants were asked to indicate which of 75 given domestic appliances they personally had in their household and whether they had read the respective instruction manual. In addition, they were asked to give an overall estimate of whether they typically read the instruction manuals of electric household appliances (five-point scale from 1 'never' to 5 'always', $M=2.69$, $\mathrm{SD}=1.12$, Range $=[1 ; 5]$ ). Technical control beliefs were measured by a short version of a questionnaire developed by Beier (1999). For economic reasons, Beier's short version ( 8 items) was used; this assesses technical control beliefs as an unidimensional construct (e.g. positive belief: 'I can solve most technical problems by myself', negative belief: 'Technical devices are often difficult to understand and handle'). Items had to be rated on a five-point Likert scale $(\mathrm{M}=2.65, \mathrm{SD}=0.38)$. It should be noted that although Beier (1999) reported a very high internal consistency for the short scale (Cronbach's Alpha $=0.89$ ), the consistency analysis here evinced an extremely low coefficient (Cronbach's Alpha $=0.25$ ). As a general indicator of environmental concern, one item was used ('I am concerned about the environment'; five-point Likert scale; $\mathrm{M}=3.71$, $\mathrm{SD}=0.97$ ). By means of median split $(\mathrm{MD}=4.00)$ the sample was divided into participants with low and high 
environmental concern. To have an indicator of product complexity and of the difficulty of putting the product into operation, an engineer and an expert in ergonomics rated the 75 domestic appliances on these dimensions. Interrater reliability was acceptable (complexity: $\kappa=0.75$; difficulty of putting the appliance into operation: $\kappa=0.49$ ).

\subsection{Results}

2.2.1. Observational data on the use of the instruction manual: Overall, 14 out of 42 participants $(33.3 \%)$ read the instruction manual before putting the vacuum cleaner into operation. To test the assumption that situational cues on the instruction manual promote reading probability, those participants who were given a cue on the instruction manual were compared with those who did not receive a cue. Whether the cue contained aspects of security or energy-saving behaviour made no difference for the usage probability since in both groups the probability was $43 \%\left(\chi^{2}[1\right.$, $n=28]=0.00$, n.s.; for the differences between participants high and low in ecological concern see below). Therefore, the two cue groups were collapsed into one. As expected, participants who received a cue concerning the instruction manual used it more often than those who received no cue $\left(\chi^{2}[1, n=42]=3.43, p<0.05\right.$, one-tailed; see figure 2).

In addition, when comparing participants with high and low environmental concern, a significant difference resulted: Those participants from the ecology prime group with high environmental concern did use the manual significantly more often $(63 \%)$ than those low on environmental concern $\left(17 \% ; \chi^{2}[1, n=14]=2.94\right.$, $p<0.05$, one-tailed). Against the predictions, neither gender differences (reading probability for men: $35 \%$, reading probability for women: $32 \%: \chi^{2}[1, n=42]=0.05$, n.s.) nor a relation to technical control beliefs (t[40] $=1.22$; n.s.) were found when comparing those who read (technical control beliefs: $\mathrm{M}=2.55, \mathrm{SD}=0.35$ ) and those who did not read (technical control beliefs: $\mathrm{M}=2.71, \mathrm{SD}=0.39$ ) the user manual during the laboratory observation.

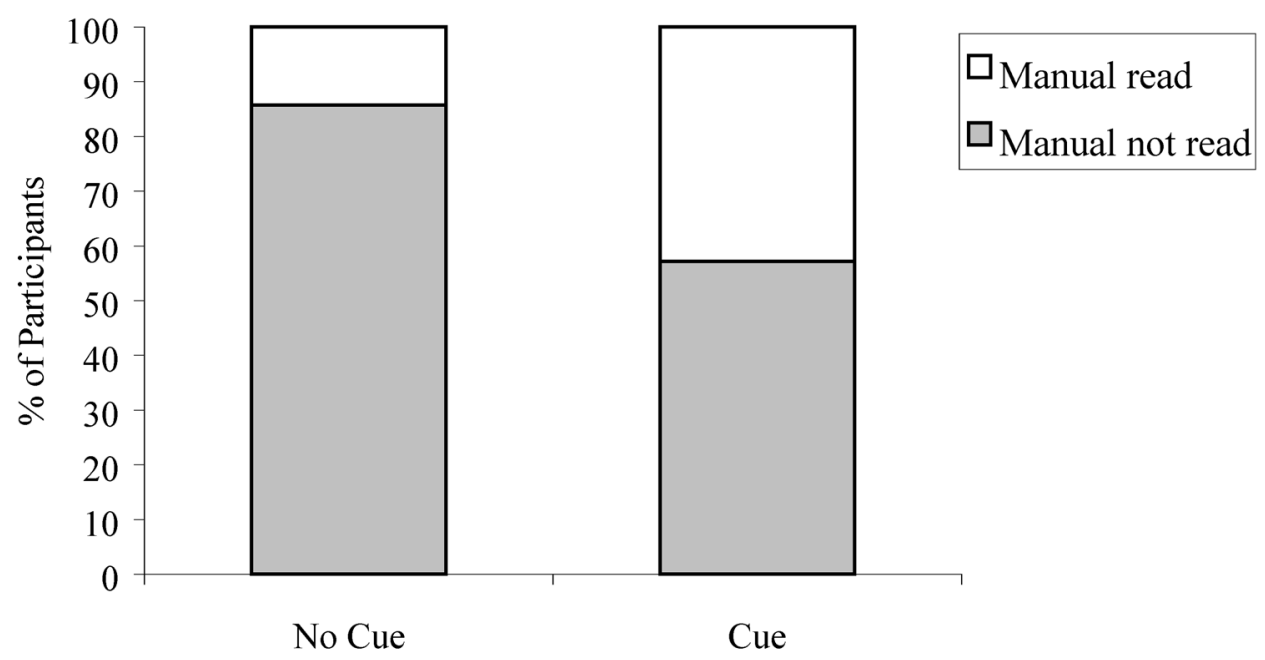

Figure 2. Situational cues and the use of the instruction manual. 


\title{
Consumers' use of written product information
}

\author{
Bettina S. Wiese $\dagger^{*}$, Jürgen Sauer $\ddagger$ and Bruno Rüttinger $\ddagger$ \\ $\dagger$ Department of Psychology, University of Koblenz-Landau, Fortstrasse 7, \\ D-76829 Landau, Germany \\ Institute of Psychology, Darmstadt University of Technology, Hochschulstrasse \\ 1, D-64289 Darmstadt, Germany
}

Keywords: Product information, Instruction manual, Consumer products, Ecological behaviour.

\begin{abstract}
Two studies were conducted to investigate the predictive role of person-specific, product-specific, and situation-specific influences on the use of instruction manuals in the field of electrical consumer products. In a laboratory study, 42 participants were observed while putting a vacuum cleaner into operation. Situational primes (i.e., receiving a verbal cue that the packaging contains an instruction manual) increased the probability of the user manual being read. Additional verbal information that the manual contains information on energysaving behaviours was especially motivating for persons with high environmental concern. Self-report data, collected on a wide range of products, suggest that product complexity is the best predictor of instruction manual use. In a second study with 30 participants, different positions of product labels were compared, i.e. placing the information on the packaging or directly onto the product. Information placed directly onto the product had a significantly higher influence on participants' actual behaviour than providing the same information on the packaging.
\end{abstract}

\section{Introduction}

Whoever buys a technical product will receive an instruction manual. In psychological research, user manuals are mainly investigated from the perspective of instructional psychology (cf. Konoske and Ellis 1991, Ballstaedt 1997) by focusing on the question of how product information should be presented to be understandable and recalled (e.g. Haney 1969, Bieger and Glock 1986, Young and Wogalter 1990, Wogalter and Vigilante 2003). This topic is also dealt with in various popular books on how to write user manuals (e.g. Weiss 1985).

How much, however, do consumers actually make use of instruction manuals? Gebert (1988) conducted a series of studies that provided important insight into the use of instruction manuals. In a survey among visitors to a technology fair, $37 \%$ of the participants reported that they would first try to use a new product without referring to external help. Another study evinced that about a third of the users read only parts of the manual. This is not surprising since many customers think that instruction manuals are too technical, too complicated, and too difficult to read (see Gebert 1988). It is interesting to note that a number of readers reported that they 
In future studies, consideration might be given to Heslin and Johnsons' (1992) distinction between dispositional and product involvement. These authors suppose that consumers spend more time learning about a product when (a) interested in learning about things in general (i.e., dispositional involvement) or (b) feeling involved in a specific product class (i.e., product involvement; see also Bloch and Richins 1983). It is possible to speculate on whether dispositional and product involvement predict instruction manual use. As Heslin and Johnson (1992) pointed out, it also has to be taken into account that experience, interest and information need might level each other out. For example, with high product experience information need might decrease. In their own research on information processing during purchase decisions, Heslin and Johnson (1992) found that participants with high product involvement spent more time on studying product information than participants with low product involvement, but they found no effect of dispositional involvement.

As expected, there were clear product-dependent differences in the self-reported use of instruction manuals: users more often refer to instruction manuals when dealing with rather complex appliances (e.g. answering machine, video recorder) than when dealing with less complex products (e.g. coffee machine, toaster). The implication of this finding is that with regard to rather complex appliances, efforts to increase the quality of instructions are highly desirable. This is an important point as the number of appliances within a household is rising while at the same time technical innovations have led to the development of increasingly complex products (e.g. programmable appliances, operation of appliances via mobile phone). Concerning less complex products, however, such efforts might only be of minor effectiveness. Therefore, alternative ways of conveying product information should be explored with regard to less complex products.

\section{Study II: Alternative ways of presenting product information}

This study aims at comparing the effectiveness of two different ways of presenting product information, that is, putting information on the product vs. placing information on the packaging. Referring to the close-proximity principle described in ergonomics (see Wickens and Hollands 2000, Sauer et al. 2002), it is suggested that information given directly on the product has a higher probability of being read and processed by the user since it is always within sight. Some evidence for placement influences on product information processing has been found in a study by Wogalter et al. (1999) on pharmaceutical products. In samples of older adults, they found that pharmaceutical containers with cap labels were not only preferred but also led to greater knowledge than front, back or side labels.

It was decided to test the assumption of a placement effect by using information on energy-saving behaviour. Such information seems especially important since it is known that household appliances make a considerable contribution to global environmental damage (see Wenzel et al. 1997), with electricity consumption during usage being a primary cause. Again, the vacuum cleaner was used as a model product. A task analysis of vacuum cleaner utilization conducted by Rüttinger and Lasser (1998) suggested that energy wastage during operation is mainly due to the following behaviour patterns: poor work preparation, inefficient management of suction control and poor product maintenance. These aspects, therefore, will be included in the presented product information. It was hypothesized that placing this information on the product should lead to enhanced recall performance as well as to 
a higher frequency of actually carrying out the respective activities than placing the same information on the packaging.

\subsection{Methods}

3.1.1. Participants and design: The study was conducted with $n=30$ college students from the Darmstadt University of Technology (26 male; 4 female), aged between 19 and 37 years $(M=23.90$ years, $S D=4.88)$. As in Study I, participation was voluntary and not paid for. To test the assumption of a product placement effect, a one-factorial design was used, with information placement being varied at two levels: information placed on the product vs. information placed on the packaging.

3.1.2. Procedure and instruments: Again, the study took place in individual sessions in a laboratory where participants were asked to put a packed vacuum cleaner into operation and to clean a prepared room. Each session lasted about $15 \mathrm{~min}$. Participants were randomly allocated to one of two conditions: Fifteen participants received a packed vacuum cleaner with information on energy-saving behaviour directly written on the vacuum cleaner; fifteen participants received a packed vacuum cleaner with information on energy-saving written onto the packaging. The information label is presented in figure 3 .

3.1.3. Observed behaviours: To collect objective data on actual energy-saving behaviour, it was observed whether participants prepared the room before starting to clean, that is, whether they removed three objects from the floor area (two chairs, a tin lid). For each of the three observed preparing activities, participants were assigned one point. This means that they could obtain a maximum of three if they carried out all preparatory activities. In addition, it was observed whether participants reduced the power of the control setting. This activity was also suggested by the given product information (see figure 3 ). Concerning the third hint given on energy-saving behaviour (i.e., putting in a new vacuum cleaner bag when the red lamp is on), it was not expected that participants would carry this out, as the scenario (i.e., putting into operation a new vacuum cleaner) did not require it. This activity was included on the label, (a) because it has been shown to be one of the most important reasons for energy wastage during usage (see above) and (b) because the authors were also interested in recall performance (see below).

\section{How TO SAVE ENERGY}

Please remove furniture and small items first so you can clean your room comfortably and fast.

In case of moderate dirtiness, please choose a low setting of suction control.

If the red lamp is on, please put in a new vacuum cleaner bag.

Figure 3. Product label used to encourage energy-saving behaviour. 
3.1.4. Free recall performance: After completing the cleaning task, participants were asked whether they remembered any of the information related to energysaving behaviour that had been written on the vacuum cleaner/packaging. They had to remember the content of the three statements, but without having to remember the exact wording. For each statement that they could remember they were given one point (range: 0 to 3 points).

3.1.5. Self-report data: To assess environmental concern, a four-item short version of the global environmental attitude scale was used (e.g. 'I think one should stop dramatizing the current environmental situation'; $M=3.67$, $\mathrm{SD}=0.69, \quad \alpha=0.60)$ as well as a four-item short version of the domestic environmental attitude scale (e.g. 'I think exclusively buying products with ecolabels goes too far'; $\mathrm{M}=3.53, \mathrm{SD}=0.55, \alpha=0.08)$ developed by Steinheider et al. (1999). These two scales were positively intercorrelated $(r=0.37, p<0.05)$. As the domestic environmental attitude scale displayed no internal consistency, the two attitude scales were collapsed into one $(\mathrm{M}=3.60, \mathrm{SD}=0.51$, $\alpha=0.55)$.

\subsection{Results}

3.2.1. General results on behavioural and recall performance: An analysis of the observational data on preparatory activities revealed a mean frequency of $\mathrm{M}=0.70$ $(\mathrm{SD}=1.21)$ preparatory activities being carried out. It should be noted that only 6 participants carried out all three activities, whereas 21 participants carried out none. Similarly, power setting operations were rare: only 7 participants $(23.3 \%)$ actually reduced the preset power setting.

Concerning free recall performance, the result was that most participants $(83.3 \%)$ did not remember any of the given information and only 3 participants $(10.0 \%)$ remembered all three points (i.e. preparatory activities, control setting, changing vacuum cleaner bag). There were no differences between the recall frequencies of the three statements (Friedman-Test: $\chi^{2}[2]=1.00$, n.s.).

\subsubsection{Effects of information placement on observed behaviour and recall performan-} ce: Table 1 summarises the main results on the effects of information placement.

As expected, preparatory activities were observed significantly more often among those participants that received information placed directly on the vacuum cleaner than among those participants that received the same information on the packaging. However, it was not possible to confirm the assumption that the placement of the information given would also influence the probability of lowering down the control setting. Concerning the overall freerecall performance, no differences between the two placement conditions were found.

It is important to note that there was neither a significant correlation between remembering information on preparatory activities and actual preparatory behaviour $\left(r_{\text {Spearman-Brown }}=0.29, p=0.12\right)$ nor between remembering information on ecological power setting and actual power reductions $\left(\chi^{2}[1, n=30]=0.1\right.$, n.s. $)$. Finally, neither remembering $(r=-0.12$, n.s.) nor displaying (preparatory activities: $r=-0.17$, n.s.; power setting reduction: $\mathrm{t}(28)=0.35$, n.s.) energysaving behaviours was related to the degree of self-reported environmental concern. 
Table 1. Effects of information placement on operative behaviour and recall performance

\begin{tabular}{|c|c|c|c|}
\hline & \multicolumn{2}{|c|}{ Information placement } & \multirow[b]{2}{*}{ Test of significance } \\
\hline & $\begin{array}{l}\text { Packaging } \\
(n=15)\end{array}$ & $\begin{array}{l}\text { Product } \\
(n=15)\end{array}$ & \\
\hline \multicolumn{4}{|l|}{ Ecological behaviour } \\
\hline Preparatory activities ${ }^{\mathrm{a}, \mathrm{b}}$ & $\begin{aligned} \mathrm{M} & =0.27 \\
(\mathrm{SD} & =0.21)\end{aligned}$ & $\begin{aligned} \mathrm{M} & =1.13 \\
(\mathrm{SD} & =1.41)\end{aligned}$ & $\mathrm{t}(22.17)=2.07 * *$ \\
\hline Lowering of control setting & $\begin{array}{l}\text { yes: } n=4 \\
\text { no: } n=11\end{array}$ & $\begin{array}{l}\text { yes: } n=3 \\
\text { no: } n=12\end{array}$ & $\chi^{2}(1, n=30)=0.19$ \\
\hline Recall performance ${ }^{\mathrm{c}}$ & $\begin{aligned} \mathrm{M} & =0.33 \\
(\mathrm{SD} & =0.90)\end{aligned}$ & $\begin{aligned} \mathrm{M} & =0.53 \\
(\mathrm{SD} & =1.13)\end{aligned}$ & $\mathrm{t}(28)=0.54$ \\
\hline
\end{tabular}

$* * p<0.01$, one-tailed.

${ }^{\text {a }}$ Scores could range from 0 to 3 .

${ }^{\mathrm{b}}$ Since variance inhomogeneity was large, an additional non-parametric analysis was carried out: A $\chi^{2}$-test confirmed that information placement had an effect on whether or not any preparatory activities were conducted $\left(\chi^{2}[1, n=30]=3.97, p<0.01\right.$, one-tailed $)$.

${ }^{\mathrm{c}}$ Scores could range from 0 to 3 .

\subsection{Discussion}

In Study II, two alternative ways of presenting product information were compared, that is putting information onto the product vs. giving information on the packaging. As was suggested, information given on the product had a higher influence on the actual user behaviour than information given on the packaging. However, this effect was restricted to observable behaviour, whereas recall performance was left unaffected. In addition, the effect was restricted to only one of the two observed activities, that is preparatory activities such as removing furniture.

Why has recall performance not been affected by information placement? First, it is important to note that only a minority of participants did actually recall any of the advice given. Based on these data, the possibility that a higher proportion of participants remembered the information at the beginning of the trial but forgot it during the course of the experiment cannot be excluded. It is also possible that a higher performance rate would have been observed if a recognition or a cued recall had been used instead of a free recall paradigm to test memory performance. With regard to the placement hypothesis, the small proportion of participants recalling the information implies that a floor effect might have occurred. Nevertheless, can it be assumed that information given directly about the product has a higher probability of being read and processed by the user? In fact, from cognitive psychology it is known that perception can take place without awareness (see Merikle and Reingold 1991, Bornstein and Pittman 1992). Research in social cognition demonstrates that information being not intentionally or even unconsciously processed might have deep influences on judgement and self-reported attitudes (Martin and Achee 1992). In addition, and more specific to the present context, in advertising psychology, considerable evidence exists that uncontrolled information processing influences consumer behaviour (e.g. Bornstein and D'Agostino 1994; for a critical review, see Felser 1997).

Concerning observed activities, the placement effect was restricted to preparatory activities. Why is it not possible to find an effect on reductions of power control 
setting? As all participants got the hints on energy-saving behaviours in the same sequence (see figure 3), that is information on preparatory activities first, a potential order effect has to be considered. This seems to be especially plausible in a situation where attention has not been explicitely linked to the given information. It might be argued that under such circumstances, users will not attend to more than one piece of information. Although it is desirable to present action-related instructional information in the same order as actions are expected to be carried out (Smith and McMahon 1970, Dixon et al. 1988), an inversed (e.g. information about power setting before information about preparatory activities) or randomized presentation order should be implemented in further studies, allowing a test of whether the placement effect would then be generalizable over different behavioural categories (e.g. whether information about power setting reductions would be translated into behaviour more often when presented on the appliance itself than when presented on the packaging or in the instruction manual). Evidence for a possible primacy effect comes from another study conducted by Sauer et al. (2002) in which two messages(1) information about control setting, (2) information on preparatory activitieswere presented on a product label. In line with the present findings, it emerged that only the first message (i.e. information about control setting) induced behavioural change. Another explanation for the missing power-setting effect in the present study might be that participants perceived the carpet as rather dirty. The instruction of lowering the power setting, however, referred only to slight dirtiness. To be able to control for this possible alternative cause, it would have been helpful having subjective ratings of the dirtiness of the cleaning surface (see Sauer et al. 2004).

It was not possible to identify a significant association between environmental attitude and energy-saving behaviours. A similar finding emerged in the lab-based study by Sauer et al. (2004) on the ecological use of vacuum cleaners. They could not identify a significant association between pro-environmental attitude and energysaving performance (i.e. mean energy consumption per time unit) either. Although it might be argued that high environmental concern does not guarantee ecological behaviour, since an environmentally concerned individual might be low on 'operative knowledge' (i.e., knowing how to use an appliance to save energy; see Sauer et al. 2002, 2003, 2004), the present study demonstrates that even when explicitly giving operative information on ecological behaviour, environmentally concerned people did not differ from individuals with lower environmental concern. It might be speculated, therefore, that (environmental) knowledge must be given with a stronger rationale (i.e. 'reasoned' information) to change behaviour. For instance, consumers might consider vacuum cleaning not relevant to environmental conservation. Hence, it would be important to inform them that the electricity consumption of household appliances has a considerable environmental impact (see Wenzel et al., 1997). However, it is necessary to take into account that there is a trade-off between giving more detailed information about why a specific behaviour is desirable and the widely acknowledged necessity for conveying product information succinctly (Carroll et al. 1987, Lazonder and Van der Meij 1993).

\section{Concluding discussion}

The present studies demonstrate how difficult it is to communicate instructional product information to customers. Across a broad range of products, it has been shown that instruction manuals are often not read. This holds true especially for non-complex and widely used domestic appliances. It might be argued that users 
built up strong habits in handling such appliances, preventing them from referring to instruction manual information when putting into operation a new product of the same category. This is an important finding also for evaluating and planning research on how to improve the quality of instruction manuals. This research often seems to implicitly rely on the assumption of instruction manuals being read, though not thoroughly and systematically (see Young and Wogalter 1990).

A cue on the instruction manual has been effective in increasing the probability of reading instruction manuals before starting to operate a domestic appliance. However, it is still not known how effective such a priming would be in real-life settings. Although it could be imagined that cues given by sales staff enhance reading probability, it has to be taken into account that such a measure would require a highly committed salesperson. In addition, between the purchase decision and the actual use of a new product there may be a rather long interval that may decrease the probability of users remembering an advice given by a salesperson. In fact, requests to change behaviour are most effective when close in space and time to where and when the critical behaviour is expected (Gardner and Stern 1996). Therefore, it appears to be more efficient to place important information directly onto the product. This approach makes use of the 'close-proximity principle' (see Wickens and Hollands 2000, Sauer et al. 2002). Research on display location, for instance, has shown that the more centrally the display is positioned, the more frequently it is sampled (Wickens and Hollands 2000). Another important advantage of placing information directly onto the product is that, in contrast to both instruction manual booklets and information written onto the packaging, this on-product information will not be mislaid or discarded (see Wogalter et al. 1993).

In future research, it would be interesting to test whether the effectiveness of presenting instructional information directly onto the product could be increased by additional means. With regard to pharmaceutical labels attached to drug containers, for instance, Wogalter and Vigilante (2003) have recently shown that print size significantly increased information acquisition especially among older adults. In addition, concerning perceived readability, Wogalter and Vigilante (2003) demonstrated that younger as well as older adults indicated to prefer labels with a rather large print size and white space between the text lines. In the field of instruction manual warnings, Young and Wogalter (1990) found that a message conspicuously printed and accompanied by a compatible pictorial icon was better comprehended and recalled than a message not accompanied by such an icon. In another study on pharmaceutical information, Sojourner and Wogalter (1998), showed that information simultaneously presented in two forms (i.e. text and pictorials) was recalled more often than the same information (a) given by a text that was only partly accompanied by pictorials, (b) exclusively given in text form, or (c) given by pictorials alone. Although not all kinds of information are suitable for being communicated by symbols or pictures (see Robinett and Hughes 1984), consideration should be given to the additional presentation of pictorial icons. These icons not only could increase the likelihood of written information being noticed and read, but also would enable dual or redundant coding (Paivio 1975, Wickens 1992) thereby promoting processing efficiency (see Sojourner and Wogalter 1998).

It also has to be taken into account, however, that the product surface does not always allow the presentation of detailed product information (e.g. in case of small products/appliances, see Wogalter and Vigilante 2003) and that any productinformation-based intervention strategy relies on the actual willingness of the user to 
initiate or change specific behaviour patterns. Verplanken et al. (1997), for instance, have shown that individuals with strong habits are less active in acquiring new information. Since consumers are familiar with most conventional domestic appliances (e.g. vacuum cleaner, hair dryer, etc.) and have already developed wellestablished utilization habits, they may be barely motivated to work through any kind of product information (see also Wright et al. 1982). Therefore, whenever possible, a more direct focus on the user-product interface should be considered. In fact, over recent years, the area of consumer products has become an important research field for ergonomists (see Stanton 1998, Green and Jordan 1999). As it has been outlined by Sauer et al. (2001), a design-centred approach (e.g. implementing constraints such as a ecological power setting maximum; implementing feedback functions) can be expected to be especially effective in preventing unwelcome behaviour and in fostering desirable behaviour in the domestic domain.

\section{Acknowledgements}

This work was sponsored by a grant from the German Research Council (SFB-No. 392). The authors gratefully acknowledge this support. In addition, we would like to thank Brigitta Klier, Mathias Mankus, Konstanija Petrovic, Karina Schnitzer, Astrid Wollschlaeger, and Michael Zimmerlein for their assistance in data collection.

\section{References}

Ballstaedt, S.-P. 1997, Wissensvermittlung (Weinheim: Beltz).

Bandura, A. 1996, Reflections on human agency, in J. Georgas and M. Manthouli (eds), Contemporary Psychology in Europe: Theory, Research, and Applications (Seattle, WA: Hogrefe \& Huber), 194-210.

Baumert, J., Evans, R. and Geiser, H. 1998, Technical problem solving among 10-year-old students as related to science achievement, out-of-school experience, domain-specific control beliefs, and attribution patterns, Journal of Research in Science Teaching, 53, $987-1013$.

Beier, G. 1999, Persönlichkeitsmerkmale und Mensch-Technik-Interaktion, Report Psychologie, 24, 684-693.

Bieger, G. R. and Glock, M. D. 1986, Comprehending spatial and contextual information in picture-text instructions, Journal of Experimental Education, 54, 181-188.

Bloch, P. H. and Richins, M. L. 1983, A theoretical model for the study of product importance perceptions, Journal of Marketing, 47, 69-82.

Bornstein, R. F. and D'A gostino, P. R. 1994, The attribution and discounting of perceptual fluency: Preliminary tests of a perceptual fluency/attributional model of the mere exposure effect, Social Cognition, 12, 103-128.

Bornstein, R. F. and Pittman, T. S. (eds) 1992, Perception Without Awareness (New York: Guilford Press).

Carroll, J. M., Smith-Kerker, P. L., Ford, J. R. and Mazur-Rimetz, S. A. 1987, The minimal manual, Human Computer Interaction, 3, 123-153.

Dixon, P., Faries, J. and Gabrys, G. 1988, The role of explicit action statements in understanding and using written directions, Journal of Memory and Language, 27, 649 667.

Ertmer, P. A., Evenbeck, E. and Cernamo, K. S. 1994, Enhancing self-efficacy for computer technologies through the use of positive classroom experience, Educational Technology Research and Development, 42, 45-62.

Felser, G. 1997, Werbe- und Konsumentenpsychologie (Heidelberg: Spektrum Akademischer Verlag).

Gardner, G. T. and Stern, P. C. 1996, Environmental Problems and Human Behavior (Boston: Allyn \& Bacon). 
Gebert, D. 1988, Gebrauchsanweisungen als Marketing-Instrument (Wiesbaden: Forkel).

Green, W. S. and Jordan, P. W. 1999, Human Factors in Product Design (London: Taylor \& Francis).

HANEY, R. W. 1969, The effect of instructional format on functional testing performance, Human Factors, 11, 181-188.

Henry, J. W. and Stone, R. W. 1995, A structural equation model of job performance using a computer-based order entry system, Behaviour and Information Technology, 14, 163-173.

Henry, J. W. and Stone, R. W. 1997, The development and validation of computer selfefficacy and outcome expectancy scales in a nonvolitional context, Behavior Research Methods, Instruments and Computers, 29, 519-527.

Heslin, R. and Johnson, B. T. 1992, Prior involvement and incentives to pay attention to information, Psychology and Marketing, 9, 209-219.

Konoske, P. J. and Ellis, J. A. 1991, Cognitive factors in learning and retention of procedural tasks, in R. F. Dillon and J. W. Pellegrino (eds), Instruction: Theoretical and Applied Perspectives (New York: Praeger), 47-70.

Lazonder, A. W. and van der Meis, H. 1993, The minimal manual: Is less really more? International Journal of Man-Machine Studies, 39, 729-752.

Martin, L. L. and Achee, J. W. 1992, Beyond accessibility: The role of processing objectives in judgement, in L. L. Martin and A. Tesser (eds), The Construction of Social Judgements (Hillsdale, NJ: Erlbaum), 195-216.

Merikle, P. M. and Reingold, E. M. 1991, Comparing direct (explicit) and indirect (implicit) measures to study unconscious memory, Journal of Experimental Psychology: Learning, Memory, and Cognition, 17, 224-233.

Paivio, A. 1975, Perceptual comparisons through the mind's eye, Memory and Cognition, 3, $635-647$.

Robinett, F. and Hughes, A. 1984, Visual alerts to machinery hazards: A design case study, in R. Easterby and H. Zwaga (eds), Information Design: The Design and Evaluation of Signs and Printed Material (Chichester: Wiley), 405-417.

Rüttinger, B. and Lasser, M. 1998, Kunden- und nutzerorientierte Entwicklung umweltgerechter Produkte, in K. Landau (ed.), Mensch-Maschine-Schnittstellen (Stuttgart: Institut für Arbeitsorganisation), 219-223.

Sauer, J., Wiese, B. S. and Rüttinger, B. 2001, The utilization phase as a critical element in ecological design, in M. S. Hundal (ed.), Mechanical Life Cycle Handbook: Good Environmental Design and Manufacturing (New York: Marcel Dekker), 257-283.

Sauer, J., Wiese, B. S. and Rüttinger, B. 2002, Improving ecological performance of electrical consumer products: the role of design-based measures and user variables, Applied Ergonomics, 33, $297-307$.

Sauer, J., Wiese, B. S. and RÜttinger, B. 2003, Designing low-complexity electrical consumer products for ecological use, Applied Ergonomics, 34, 521-531.

Sauer, J., Wiese, B. S. and Rüttinger, B. 2004, Ecological performance of electrical consumer products: the influence of automation and information-based measures, Applied Ergonomics, 35, 37-47.

Sмiтh, K. H. and McMahon, L. E. 1970, Understanding order information in sentences: some recent work at Bell Laboratories, in G. B. Flores D'Arcais and W. J. M. Levelt (eds), Advances in Psycholinguistics (Amsterdam: North-Holland), 97-129.

Sojourner, R. J. and Wogalter, M. S. 1998, The influence of pictorials on the comprehension and recall of pharmaceutical safety and warning information, International Journal of Cognitive Ergonomics, 2, 93-106.

Stanton, N. (ed.) 1998, Human Factors in Consumer Products (London: Taylor \& Francis).

Steinheider, B., Fay, D., Hilburger, T., Hust, I., Prinz, L., Vogelgesang, F. and Hormuth, S. 1999, Soziale Normen als Prädiktoren von umweltbezogenem Verhalten, Zeitschrift für Sozialpsychologie, 30, 40-56.

Torkzadeh, R., Pflughoeft, K. and Hall, L. 1999, Computer self-efficacy training effectiveness and user attitudes: An empirical study, Behaviour and Information Technology, 18, $299-309$.

Verplanken, B., Aarts, H. and van Knippenberg, A. 1997, Habit, information acquisition, and the process of making travel mode choices, European Journal of Social Psychology, 27, $539-560$. 
Weiss, E. H. 1985, How to Write a Usable User Manual (Philadelphia: ISI Press).

Wenzel, H., Hauschild, M. and Alting, L. 1997, Environmental Assessment of Products (Vol. 1) (London: Chapman and Hall).

Wickens, C. D. 1992, Engineering Psychology and Human Performance, 2nd edn. (New York: Harper Collins).

Wickens, C. D. and Hollands, J. G. 2000, Engineering Psychology and Human Performance, 3rd edn. (New Jersey: Prentice-Hall).

Wogalter, M. S. and Vigilante, W. J. 2003, Effects of label format on knowledge acquisition and perceived readability by younger and older adults, Ergonomica, 46, 327-344.

Wogalter, M. S., Forbes, R. M. and Barlow, T. 1993, Alternative product label designs: increasing the surface area and print size, Proceedings of Interface 93 (Santa Monica, CA: Human Factors and Ergonomics Society), 181-186.

Wogalter, M. S., Magurno, A. B., Dietrich, D. A. and Scott, K. L. 1999, Enhancing information acquisition for over-the-counter medications by making better use of container surface space, Experimental Aging Research, 25, 27 - 48.

Wright, P., Creighton, P. and Threlfall, S. M. 1982, Some factors determining when instructions will be read, Ergonomics, 25, 225-237.

Young, S. L. and Wogalter, M. S. 1990, Comprehension and memory of instruction manual warnings: Conspicuous print and pictorial icons, Human Factors, 32, 637-649. 